\title{
The second proof of the Fermat's Last theorem (elementary aspect)
}

\author{
PROF. DR. K. RAJA RAMA GANDHI ${ }^{1}$ AND REUVEN TINT ${ }^{2}$ \\ Resource person in Math for Oxford University Press and Professor at BITS-Vizag ${ }^{1}$ \\ Number Theorist, |srael $\left.\right|^{2}$ \\ Email: editor126@gmail.com, reuven.tint@gmail.com
}

\begin{abstract}
We give a second proof of Fermat's Last theorem without reference to the closure of numerical systems with respect to the operation of superposition.
\end{abstract}

\section{Theorem.}

We must to prove that the equation

$$
x^{n}+y^{n}=z^{n}
$$

has no solutions in natural numbers (positive integer) $\mathrm{x}, \mathrm{y}, \mathrm{z}, \mathrm{n}$ for $\mathrm{n}>2$.

Second proof.

\section{The statement:}

Equation

$$
x^{n}+y^{n}=z^{n}
$$

is solvable in natural numbers, if the system of equations

$$
\left\{\begin{array}{c}
2^{\mu} n^{\vartheta}-2^{\mu^{\prime}}(n-1)^{\vartheta^{\prime}}=1 \quad[\mathbf{A}] \\
2^{\mu^{\prime}}(n-1) \vartheta^{\prime}=1
\end{array}\right.
$$

is consistent. It is consistent only for

$$
\mu^{\prime}=\vartheta^{\prime}=0
$$

It follows, that the system has only two solutions

$$
\begin{aligned}
& 2^{0} 1^{1}-2^{0} 0^{0}=1 \text { and } n=1 \\
& 2^{0} 2^{1}-2^{0} 1^{0}=1 \text { and } n=2 .
\end{aligned}
$$

If $\mu^{\prime}$ and $\vartheta^{\prime}$ not simultaneously equal to zero, then $[\mathbf{A}]$ has a number of solutions for each positive integer $\mathrm{n}>2$, in particular

and etc.

$$
\begin{aligned}
& 2^{0} 3^{1}-2^{0} 2^{1}=1 \\
& 2^{0} 4^{1}-2^{0} 3^{1}=1
\end{aligned}
$$


1.1. Second proof (p.1).

1.1. Let $\mathrm{x}>0 ; \mathrm{y}>0 ; \mathrm{z}>\mathrm{x}, \mathrm{y} ; \mathrm{n}>\mathrm{k} \geq 0$-are an arbitrary natural numbers.

Then, the equality

$$
x^{n}(y z)^{k}+y^{n}(x z)^{k}=z^{n}(x y)^{k}[1]
$$

will be proved, if

$$
\mathrm{x}^{\mathrm{n}-\mathrm{k}}+\mathrm{y}^{\mathrm{n}-\mathrm{k}}=\mathrm{z}^{\mathrm{n}-\mathrm{k}}[2]
$$

1.2. It also includes the case where

$$
x^{n}+y^{n}=z^{n}[3]
$$

1.2.1. that from [1] and [2] for $\mathrm{n}>2$ is possible only where $\mathrm{k}=0$.

1.2.2. And only for $n=2$ we obtain

$$
\begin{gathered}
x^{2}(y z)^{k}+y^{2}(x z)^{k}=z^{2}(x y)^{k} \\
x^{2-k}+y^{2-k}=z^{2-k}
\end{gathered}
$$

and $\mathrm{k}=0$ (for all $\mathrm{n}>2$ ). And $\mathrm{k}=1$, since

$$
x+y=z
$$

for arbitrary $\mathrm{x}$ and $\mathrm{y}$.

1.3. For $\mathrm{n}=\mathrm{k} 1+1 \neq 1$.

1.4. From [3]

$$
\mathrm{z}=\left(\mathrm{x}^{\mathrm{n}}+\mathrm{y}^{\mathrm{n}}\right)^{\frac{1}{\mathrm{n}}} \quad[4]
$$

Follows from [2] and [4]

1.5. $\mathrm{n}=(\mathrm{n}-\mathrm{k}) \mathrm{S}(\mathrm{S}-\mathrm{is}$ a natural number $)$ and

$$
\begin{aligned}
& \mathrm{n}=\mathrm{k} \frac{\mathrm{S}}{\mathrm{S}-1} \quad[5] \\
& \mathrm{S}=2 ; \mathrm{k}=1 ; \mathrm{n}=2 .
\end{aligned}
$$

1.6. From [5]

$$
\begin{gathered}
\mathrm{k}=\mathrm{n} \frac{\mathrm{S}-1}{\mathrm{~S}}[\mathbf{6}] ; \\
\mathrm{S}=1 ; \mathrm{k}=0 \text { and from }[6] \mathrm{n}=2
\end{gathered}
$$

1.7. Let's consider other variants.

Since

$$
\frac{1}{2^{\mu} 5^{\vartheta}}
$$

where $\mu \geq 0 ; \vartheta \geq 0 \quad$-are an arbitrary natural numbers,- a unique representation of fractions be given by finite decimal fractions, then 


$$
\mathrm{k} \frac{\mathrm{S}}{\mathrm{S}-1} \text { and } \mathrm{n} \frac{\mathrm{S}-1}{\mathrm{~S}}
$$

can be both positive integers only if

1.7.1. from [5]

$$
\mathrm{k}=\mathrm{S}^{\prime}-1=2^{\mu^{\prime}} 5^{\vartheta^{\prime}}
$$

and

1.7.2.

1.7.3. from [6]

$$
\mathrm{n}=\mathrm{S}^{\prime}=2^{\mu^{\prime}} 5^{9^{\prime}}+1
$$

1.7.4. then,

$$
\mathrm{S}=\mathrm{n}=2^{\mu} 5^{\vartheta},
$$

$$
2^{\mu^{\prime}} 5^{\vartheta^{\prime}}+1=2^{\mu} 5^{\vartheta}[7]
$$

1.7.5. and

$$
2^{\mu} 5^{\vartheta}-2^{\mu^{\prime}} 5^{\vartheta^{\prime}}=1\left[7^{\prime}\right] .
$$

1.8. Equation $\left[7^{\prime}\right]$ has only two solutions in positive integers

1.8.1.

$$
2^{0} 5^{1}-2^{2} 5^{0}=1 ; n=5 ; k=4>0 ;
$$

therefore, $\mathrm{n} \neq 5$ ( $\mathrm{p}$ 1.2.1.).

1.8.2. It remains only to

$$
2^{1} 5^{0}-2^{0} 5^{0}=1 \text { and } \mathrm{n}=2 ; \mathrm{k}=1 .
$$

1.8.2.1. Further, we consider the equations

$$
\mathrm{x}^{\mathrm{n}}+\mathrm{y}^{\mathrm{n}}=\mathrm{z}^{\mathrm{n}}
$$

for $n>2$,using the following system of equations:

$$
\begin{gathered}
\left\{\begin{array}{c}
x^{n}(y z)^{n-1}+y^{n}(x z)^{n-1}=z^{n}(x y)^{n-1} \quad[8], \text { if } \\
x+y=z[9]
\end{array}\right. \\
\left\{\begin{array}{c}
x^{n}(y z)^{n-2}+y^{n}(x z)^{n-2}=z^{n}(x y)^{n-2} \\
x^{2}+y^{2}=z^{2}[11]
\end{array}\right.
\end{gathered}
$$

for arbitrary natural $\mathrm{n} \geq 1$ and $\mathrm{n} \geq 2$, and within each pair [8] and [9], [10] and [11] accordingly $x, y, z$ are equal in magnitude. 
Examples:

$$
\begin{aligned}
& \left\{\begin{array}{c}
3^{2}(4 \times 7)^{1}+4^{2}(3 \times 7)^{1}=7^{2}(3 \times 4)^{1} \text {, as } \\
3+4=7 \text {, but } 3^{2}+4^{2} \neq 7^{2}
\end{array}\right. \\
& \left\{\begin{array}{c}
3^{3}(4 \times 5)^{1}+4^{3}(3 \times 5)^{1}=5^{3}(3 \times 4)^{1} \\
3^{2}+4^{2}=5^{2} \text {, but } 3^{3}+4^{3} \neq 5^{3} .
\end{array}\right. \\
& \left\{\begin{array}{c}
3^{3}(4 \times 5)^{2}+4^{3}(3 \times 5)^{2} \neq 5^{3}(3 \times 4)^{2} \text {, as } \\
3+4 \neq 5
\end{array}\right. \\
& \left\{\begin{array}{c}
3^{4}(4 \times 5)^{2}+4^{4}(3 \times 5)^{2} \neq 5^{4}(3 \times 4)^{2} \\
3^{2}+4^{2}=5^{2} \text {, but } 3^{4}+4^{4} \neq 5^{4} .
\end{array}\right. \\
& \left\{\begin{array}{c}
3^{4}(4 \times 5)^{3}+4^{4}(3 \times 5)^{3} \neq 5^{4}(3 \times 4)^{3} \text {, as } \\
3+4 \neq 5 .
\end{array}\right.
\end{aligned}
$$

and so on consecutively ascending up to the $n<\infty$ (infinity).

1.9. Confirmation of the correctness of (p.1.8.1.) using the following variant of the proof:

1.9.1. If

$$
x^{5}+y^{5}=z^{5}
$$

would be a solution in positive integers, then the equality

$$
x^{5}(y z)^{1}+y^{5}(x z)^{1}=z^{5}(x y)^{1}
$$

would be satisfied, if

and

$$
\mathrm{x}^{5-1}+\mathrm{y}^{5-1}=\mathrm{z}^{5-1}
$$

$$
\mathrm{x}^{4}+\mathrm{y}^{4}=\mathrm{z}^{4} \quad[12]
$$

But as yet proved Fermat, [12] has no solutions in positive integers.

1.10. This completes the proof of Fermat's Last theorem without reference to the closure of numerical systems with respect to the operation of superposition, that is

$$
x^{n}+y^{n}=z^{n}
$$

has no solutions in positive integers for $\mathrm{n}>2$.

1.11. Now, given that $2^{\mu^{\prime}} 5^{\vartheta^{\prime}}$ may be both even and odd [7] if and only if

$$
\left(2^{\mu^{\prime}} 5^{\vartheta^{\prime}}\right)^{0}=\left[2^{\mu^{\prime}}(\mathrm{n}-1)^{\vartheta^{\prime}}\right]^{0}=2^{0}(\mathrm{n}-1)^{0}=1
$$

where $n$ is an arbitrary natural number, perhaps an approval of $(\mathrm{p} 1)$. 
1.12. Combining [1] and [2], we get

$$
(n-k) s=k, n=k \frac{s+1}{s}, \mathrm{~s}=1, \mathrm{k}=1, \mathrm{n}=2
$$

and

$$
k=n \frac{s}{s+1}, s=1, n=2, k=1 \text {. }
$$

\section{References:}

[1] H.Davenport, "The Higher Arithmetic”, Moscow, 1965.

[2] V. Sierpiński, “250 Problems in Elementary Number Theory”, Moscow, 1968.

[3] U. Davidov, " Problems and exercises in theoretical arithmetic of whole numbers ", Minsk, 1963.

[4] A. Kurosh, “Higher Algebra”, “ Science”, Fizmatgiz, Moscow, 1971.

[5] Н.Н. Воробьев, “Признаки делимости”, “ Science”, Fizmatgiz, Moscow, 1974.

[6] V. Sierpiński, “О решении уравнений в целых числах”, Fizmatgiz, Moscow, 1961. 